\title{
Vibration response of railway cable-stayed bridges under high- speed train braking loads
}

\author{
Long $\mathrm{Lu}^{1, *}$ \\ ${ }^{1}$ College of Environment and Civil Engineering, Chengdu University of Technology, Chengdu, China
}

\begin{abstract}
With the increase of the running speed of high-speed trains, the longitudinal vibration of the long span railway cable-stayed bridge under train loads has increased significantly. And the probability of high-speed train braking is greater than earthquake. The excessive vibration response will affect the serviceable of the cable-stayed bridge. Fluid viscous dampers (FVDs) and elastic cables (ECs) which are widely used in seismic design of the bridge are adopted to control the longitudinal vibration response of the cable-stayed bridge induced by train braking loads. The influence of the design parameters of FVDs and ECs on the response of the bridge is studied. And the effectiveness of FVDs and ECs on mitigating the longitudinal response of the bridge is also discussed. It is found that installing FVDs and ECs between the deck and the tower is very efficient in reducing the longitudinal vibration of the railway cable-stayed bridge subjected to train braking loads, especially the longitudinal displacement of the deck and the bending moment of the tower.
\end{abstract}

\section{Introduction}

Cable-stayed bridges are currently popular in the world. With the development of the high-speed railway, many railway cable-stayed bridges are applied to the construction in China. When the train on the bridge, the longitudinal vibration will happen, especially train braking condition. The normal operation condition of the bridge can be affected by the longitudinal vibration of the deck[1]. And the probability of train braking is significantly greater than that of earthquake, especially the high-speed train. When there are no longitudinal connection between the tower and the deck of the cablestayed bridge, the longitudinal vibration is obvious. Thus, the longitudinal vibration of the cable-stayed bridge subjected to train braking must be controlled by various effective devices.

In order to restrain the longitudinal vibration of the cable-stayed bridge, various devices were installed between the deck and the tower, such as fluid viscous dampers (FVDs), elastic cables(ECs) and metallic yield damper[2-5]. The passive hybrid control systems were employed to mitigate the seismic response of a cablestayed bridge by Soneji[2], it demonstrated that seismic response of an isolated cable-stayed bridge were significantly reduced by FVDs, and the nonlinear FVDs were more effective. A study was performed on the seismic response of a cable-stayed bridge with friction and viscous dampers, it was found that viscous dampers were beneficial to reduce the seismic response of the bridge[3]. Zhu[4] found that FVDs were very efficient in reducing the seismic response of the cable-stayed bridge under randomly generated earthquake loads, especially the nonlinear FVDs. $\mathrm{Xu}$ [5] used shake table experiment to verify the effect YSDs and FVDs on reducing the transverse and longitudinal seismic response of the cable-stayed bridge, the combination system of YSDs and FVDs was applied in the bridge for better seismic performance of the bridge.

Previous studies focused on the seismic response of the bridge. Meanwhile, the longitudinal vibration induced by vehicle braking was investigated by a few researchers. MR dampers as the active control method were used in a cable-stayed bridge to control the longitudinal dynamic response under train braking and moving loads[6, 7], it demonstrated that the use of the MR dampers in the bridge was an effective measure to control the longitudinal vibration of the bridge deck. Shan[8] found that FVDs with reasonable parameters were effective to mitigate the longitudinal response of the cable-stayed bridge under train braking loads and it was well to dissipate earthquake energy. Yang[9] investigated the effect of MR dampers on controlling the response of a suspension bridge under vehicle braking loads and earthquake, it showed that the performance of the bridge with a mixed control system was good.

However, these previous literatures referred the longitudinal vibration of the bridge focus on the seismic loads. Although some researchers investigate the longitudinal vibration under train braking, it is limited to the traditional trains which the speed is low. With the increase of train speed, the longitudinal vibration of the cable-stayed bridge induced by the train braking becomes more obvious. This paper presents the longitudinal vibration of the cable-stayed bridge subjected to high-speed train braking. The influence of

\footnotetext{
*Corresponding author: longl@cdut.edu.cn
} 
the parameters of FVDs and ECs on the response of the bridge is studied. Furthermore, the effectiveness of FVDs and ECs on mitigating the longitudinal vibration of the bridge is also discussed.

\section{Train braking loads}

The combination braking system composed of pneumatic and elcetromagic braking systems is used for $\mathrm{CRH} 2$ high-speed train. The braking force is applied to the train according to the predetermined deceleration during train braking. Fig. 1 shows the relation of deceleration to speed for the emergency braking of the train[10].

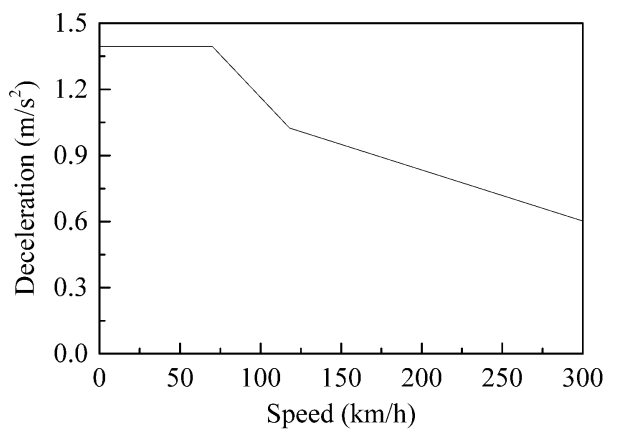

Fig. 1. Relation of deceleration to speed

The retardation force on the train is

$$
F=B+W=m a=m \ddot{x}(t)
$$

Where $m, a$ is the mass and deceleration of the train, respectively; $W$ is the resistance.

For the speed of $0 \sim 70 \mathrm{~km} / \mathrm{h}, a=1.3950$;

$70 \sim 118 \mathrm{~km} / \mathrm{h}, a=-0.0077292 \times V+1.9360$;

$118 \sim 200 \mathrm{~km} / \mathrm{h}, a=-0.0023187 \times V+1.2976$.

The resistance is written as [10]

$$
\begin{aligned}
W & =W_{0} \times m g=\left(A+B V+B V^{2}\right) \times m g \\
& =\left(A+B \dot{x}(t)+C(\dot{x}(t))^{2}\right) \times m g
\end{aligned}
$$

Where $V$ is the speed of the train; $x(t)$ is the braking distance; the value of $A, B$ and $C$ is $0.88,0.00744$ and 0.000144 , respectively[10]. to

Equation (2) is substituted into Equation (1), leading

$$
B(t)=m a-\left(A+B \dot{x}(t)+C(\dot{x}(t))^{2}\right) \times m g
$$

It is assumed that two parallel trains move on the bridge during train braking and stop at the end of the bridge. Fig. 2 shows time-histories of braking force. It can be seen that the braking force increases with time and then is invariant, and the maximum value for different initial speeds is the same.

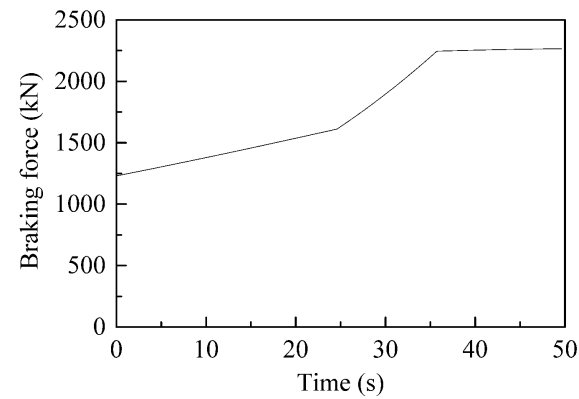

(a) Initial speeds $\mathrm{V}=200 \mathrm{~km} / \mathrm{h}$



(b) Initial speeds $V=300 \mathrm{~km} / \mathrm{h}$

Fig. 2. Time-histories of braking force

\section{Bridge Model}

A semi-harp cable-stayed bridge with a main span of $1092 \mathrm{~m}$ is used to study the dynamic response of the bridge due to train braking loads. The layout of the cable-stayed bridge is shown in Fig. 3. The two towers are made of reinforced concrete with the height of $325 \mathrm{~m}$. The deck formed by truss girder is $35 \mathrm{~m}$ in width and 16 in height. There are 432 cables which are equally anchored to the deck with the distance of $14 \mathrm{~m}$.

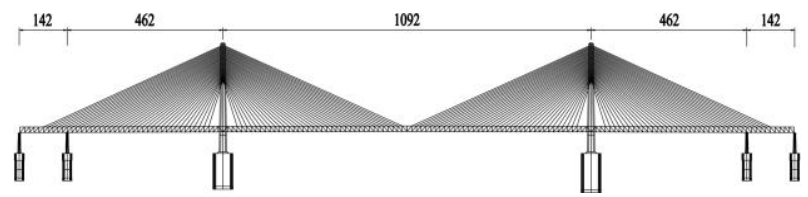

Fig. 3. The layout of the cable-stayed bridge

The FEA model for the bridge is developed, as shown in Fig. 4. The frame element is used to model towers, piers and the deck. Cables are modeled as the truss elements, and the nonlinear behavior induced by cable sagging is considered by an equivalent modulus of elasticity [3]. In the longitudinal direction, to control the response of the bridge under train braking loads, FVDs and ECs are installed between the deck and the tower in this paper. The force produced by the damper is[3]

$$
F=C \operatorname{sign}(v)|v|^{\alpha}
$$

Where $C, v, \alpha$ is the damping coefficient, relative velocity and velocity exponent, respectively[3].

The force produced by elastic cables is

$$
F=K u
$$

Where $K$ and $u$ is the stiffness and the relative displacement.

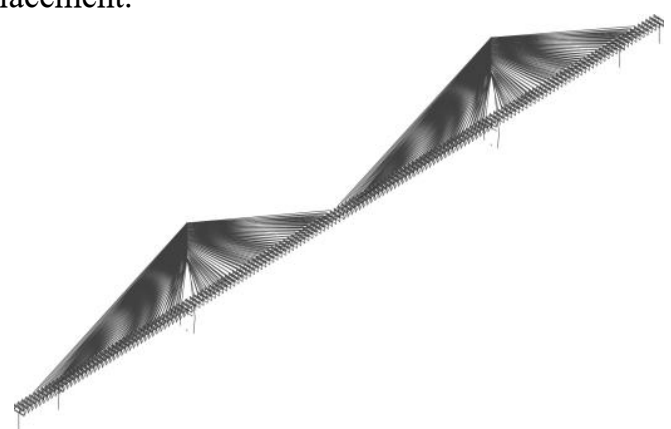

Fig. 4. FEA model 


\section{Response of the cable-stayed bridge under train braking loads}

\subsection{Effect of FVDs on the response of the bridge}

The effect of FVDs on the response of the bridge under train braking forces is studied. The value of $C$ varies from 0 to 40000 while $\alpha$ is $0.3,0.5,1.0$. The initial train speed is $200 \mathrm{~km} / \mathrm{h}$ and $300 \mathrm{~km} / \mathrm{h}$. Fig. 5 shows variation of the response of the bridge with $C$ and $\alpha$ under train braking loads.

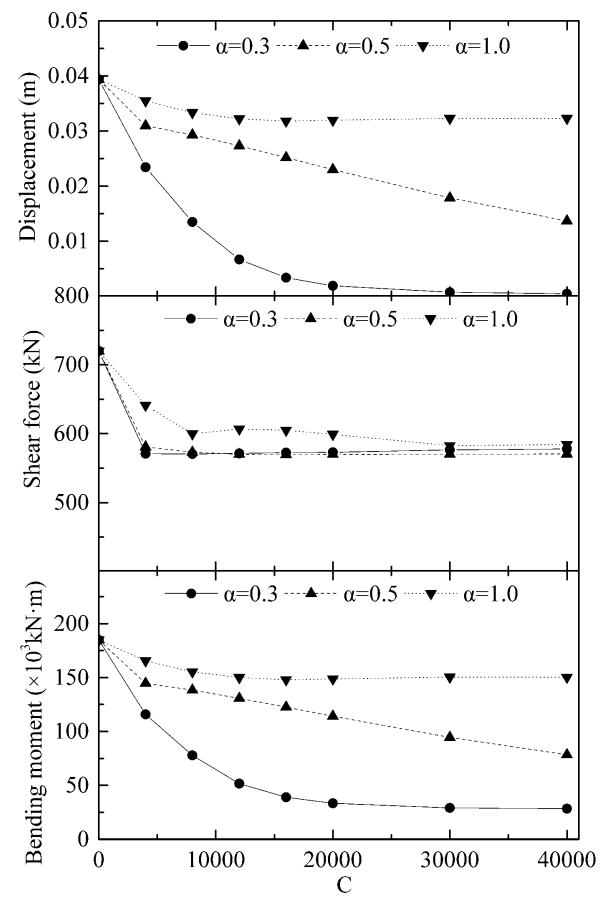

(a) $\mathrm{V}=200 \mathrm{~km} / \mathrm{h}$

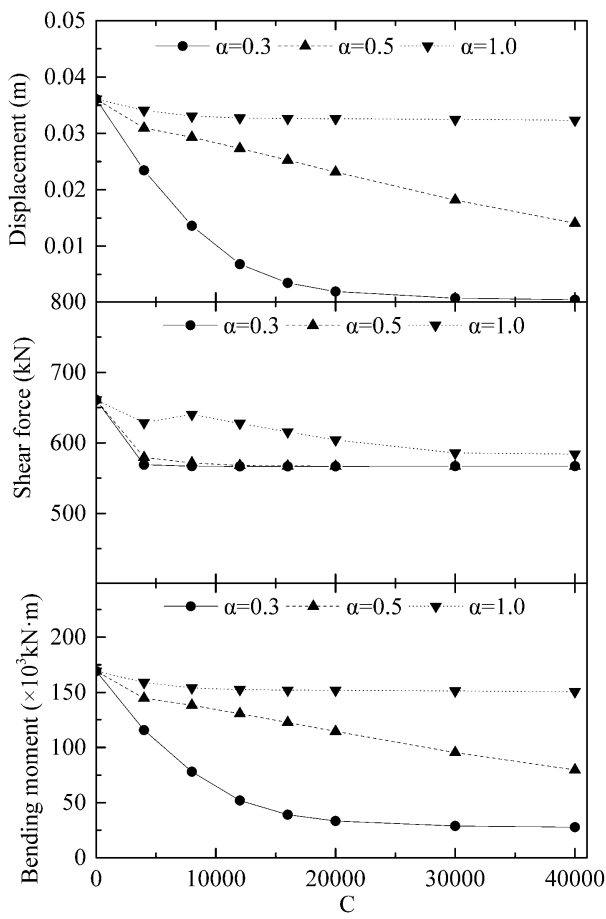

(b) $\mathrm{V}=300 \mathrm{~km} / \mathrm{h}$

Fig. 5. Variation of the response of the bridge with $C$ and $\alpha$ under train braking loads
As shown in Fig. 5, the tendency of the response with $C$ and $\alpha$ is not sensitive to the initial speed. With the increase of $C$, the longitudinal displacement of the deck firstly decreases and then is insensitive to $C$, and it obviously decreases with decreasing $\alpha$. The shear force at the bottom of the tower firstly decreases with the increase of $C$ and then tends to be constant, the effect of $\alpha$ on the shear force is slightly. The tendency of the bending moment of the tower with $C$ and $\alpha$ is same to that of the longitudinal displacement of the deck.

The results indicate that the use of FVDs is beneficial for the reduction in dynamic response of the cable-stayed bridge under high-speed train braking loads, especially the longitudinal displacement of the deck and the bending moment of the tower. And FVDs with smaller $\alpha$ are more effective to reduce the response of the cablestayed bridge.

\subsection{Effect of ECs on the response of the bridge}

The effect of ECs on the response of the bridge under train braking is studied. The value of $K$ varies from 0 to $10^{7} \mathrm{kN} / \mathrm{m}$. The initial train speed is $200 \mathrm{~km} / \mathrm{h}$ and $300 \mathrm{~km} / \mathrm{h}$. Fig. 6 shows variation of the response of the bridge with $K$ under train braking loads.



Fig. 6. Variation of the response of the bridge with $K$ under train braking loads

As seen in Fig. 6, the dynamic response of the bridge decreases with increasing the initial speed and then becomes insensitive. The longitudinal displacement of the deck and the bending moment of at the bottom of the tower decrease with $K$, and the decrease rate is significantly when the $K$ is in the range of $1 \times 10^{4} \mathrm{kN} / \mathrm{m}$ to $5 \times 10^{5} \mathrm{kN} / \mathrm{m}$. As the $K$ increases, the shear force at the bottom of the tower firstly slightly increases and then decreases. 
It is found that the use of ECs is beneficial to reduce the response of the cable-stayed bridge under high-speed train braking loads, especially the longitudinal displacement of the deck and the bending moment of the tower, the effectiveness is better when the $K$ is greater than $5 \times 10^{5} \mathrm{kN} / \mathrm{m}$.

\subsection{Effectiveness of FVDs and ECs on controlling the response of the bridge}

FVDs and ECs are usually to mitigate seismic response of the cable-stayed bridge. As stated above, the responses of the cable-stayed bridge under train braking loads are influenced by parameters of FVDs and ECs. Thus, the effectiveness of FVD and ECs with optimum parameters on controlling the response of the bridge is investigated. Table 1 shows the peak responses of the cable-stayed bridge. The value of $\alpha$ and $C$ for FVDs is 0.3 and 20000, and the value of $K$ for ECs is $5 \times 10^{5} \mathrm{kN} / \mathrm{m}$. The initial speed of the trian is $200 \mathrm{~km} / \mathrm{h}$ and $300 \mathrm{~km} / \mathrm{h}$.

From Table 1, when FVDs are installed between the deck and the tower, the longitudinal displacement of the deck, the shear force and the bending moment of at the bottom of the tower is reduced by $94.7-95.2 \%, 14.2 \%-$ $20.4 \%$ and $80.5 \%-82.2 \%$, respectively. For the response of the bridge installed ECs, the reductions in the longitudinal displacement of the deck and the shear force of the tower are $93.4 \%, 13.1 \%-13.7 \%, 78.3 \%-78.6 \%$, respectively. It is concluded that FVDs and ECs with optimum parameters are effective to control the response of the cable-stayed bridge under train braking loads, and the effectiveness is better for the longitudinal displacement of the deck and the bending moment of the tower. Compared with the bridge without longitudianl connection between the deck and the tower, the effect of the initial speed of the train on the response of the cablestayed bridge with FVDs and ECs becomes slightly.

Table 1. Peak responses of the cable-stayed bridge.

\begin{tabular}{|c|c|c|c|c|c|c|}
\hline \multirow{2}{*}{$\begin{array}{c}\text { Response } \\
\text { quantity }\end{array}$} & \multicolumn{2}{|c|}{ Without } & \multicolumn{2}{c|}{ FVDs } & \multicolumn{2}{c|}{ ECs } \\
\cline { 2 - 7 } & 200 & 300 & 200 & 300 & 200 & 300 \\
\hline$D(\mathrm{~m})$ & 0.0394 & 0.0361 & 0.0019 & 0.0019 & 0.0026 & 0.0024 \\
\hline$V(\mathrm{kN})$ & 720.1 & 660.9 & 573 & 566.7 & 625.7 & 570.2 \\
\hline$M\left(\times 10^{3} \mathrm{kN} \cdot \mathrm{m}\right)$ & 184.9 & 169.3 & 33.3 & 33.3 & 40.2 & 36.3 \\
\hline
\end{tabular}

\section{Conclusions}

FVDs and ECs commonly used in seismic design of the bridge are adopted to mitigate the longitudinal response of the cable-stayed bridge under high-speed braking loads, the conclusions are as follows:

(1) The FVDs with smaller $\alpha$ are more beneficial to reduce the dynamic response of the cable-stayed bridge under high-speed train braking loads, especially the longitudinal displacement of the deck and the bending moment of the tower.

(2) The longitudinal displacement of the deck and the bending moment of the tower of the bridge under highspeed train braking loads can be effectively reduced by ECs while the bending moment of the tower is limited, and the effectiveness is better when the $K$ is greater than
$5 \times 10^{5} \mathrm{kN} / \mathrm{m}$.

(3) The application of FVDs and ECs with optimum parameters is efficient in controlling the longitudinal vibration of the cable-stayed bridge under high-speed train braking loads. And the influence of the initial speed on the response of the bridge with FVDs and ECs becomes slightly.

\section{Acknowledgements}

This work was supported in part by A Project Supported by Scientific Research Fund of SiChuan Provincial Education Department (No.18ZB0071); and Scientific Research Start Foundation of Chengdu University of Technology (No. 10900-KYQD-06455).

\section{References}

1. J. Zhang, D.J. Wu, Q. Li, Eng. Struct. 83, 62-73 (2015)

2. B.B. Soneji, R.S. Jangid, Eng. Struct. 29, 57-70 (2007)

3. T.S. Vader, C.C. McDaniel, J. Bridge Eng. 12, 373379 (2007)

4. J. Zhu, W. Zhang, K.F. Zheng, H.G. Li, Pract. Period. Struct. Des. Constr. 21, 04015006 (2015)

5. Y. Xu, R.L. Wang, J.Z. Li, J. Bridge Eng. 21, 04016092 (2016)

6. W.L. Qu, S.Q. Qin, J.W. Tu, J. Liu, Q. Zhou, H.B. Cheng, Y.L. Pi, Smart Mater. Struct. 18, 125003 (2009)

7. J. Liu, W.L. Qu, Y.L. Pi, J. Vib. Control 16, 801825 (2010)

8. D.S. Shan, Y. He, Q. Li, Adv. Mater. Res. 255-260, 1795-1799 (2011)

9. M.G. Yang, C.S. Cai, J. Vib. Control 22, 3659-3678 (2016)

10. S.G. Wei, B.G. Cai, J.J. Wang, J. Wang, L. Wang, J. Traffic Transp. Eng. 11 41-47 (2011) 